\title{
Expression of cytochrome CYP2B1/2 in nonpregnant, pregnant and fetal rats exposed to tobacco smoke ${ }^{\star}$
}

\author{
Piotr Czekaj $^{1 \bowtie}$, Anna Wiaderkiewicz ${ }^{1}$, Ewa Florek $^{2}$ and Ryszard Wiaderkiewicz ${ }^{1}$ \\ ${ }^{1}$ II Department of Histology and Embryology, Silesian Medical Academy, Katowice, Poland; \\ ${ }^{2}$ Department of Toxicology, Medical Academy, Poznań, Poland
}

Received: 20 September, 2000; revised: 13 November, 2000; accepted: 5 December, 2000

Key words: cytochrome P450, CYP2B1/2, CYP2B6, tobacco smoke, pregnancy, rats

\begin{abstract}
Four-month-old female Wistar rats were exposed for 20 days to tobacco smoke obtained from non-filter cigarettes. During the exposure, concentration of tobacco smoke was monitored indirectly by measuring the CO level $\left(1500 \mathrm{mg} / \mathrm{m}^{3}\right.$ air). The efficacy of exposure was assessed by measuring urine nicotine and cotinine levels. Cigarette smoke did not change total cytochrome $\mathrm{P450}$ and $b_{5}$ protein levels in any of the organs studied, and most of these organs did not show any changes in the activity of reductases associated with these cytochromes. Following exposure to tobacco smoke, fetal rat liver expressed CYP2B1/2 protein; in newborns (day 1) both liver and lung showed CYP2B1/2 protein expression and very low pentoxyresorufin $O$-dealkylase activity. Western blot analysis of adult liver, lung, heart, but not of brain microsomes, showed that tobacco smoke induced CYP2B1/2 in both nonpregnant and pregnant rats, though its expression was lower in the livers and hearts of pregnant females. In the rat and human placenta, neither rat CYP2B1/2 nor human CYP2B6 showed basal or tobacco smoke-induced expression at the protein level. This study shows clearly that the expression of CYP2B1/2, which metabolizes nicotine and some drugs and activates carcinogens, is controlled in rats by age-, pregnancy-, and tissue-specific regulatory mechanisms.
\end{abstract}

The cytochrome CYP2B subfamily inducible by phenobarbital (PB) and other structurally unrelated compounds is widespread in rodents, in contrast to the human orthologous form CYP2B6 that exhibits low expression in liver and extrahepatic tissues and its role is unclear [1]. Both rat liver CYP2B1/2 and human liver CYP2B6 show catalytic activity to-

\footnotetext{
${ }^{\star}$ This paper was presented at the Symposium of the Polish Society of Toxicology: "The Metabolism of Drugs and Xenobiotics" held in Bukowina Tatrzańska on 31 May to 2 June 2000.

${ }^{凶}$ Correspondence should be addressed to: Dr. Piotr Czekaj, Medyków 18, 40-752 Katowice; Poland e-mail: pcz@slam.katowice.pl
}

Abbreviations: $\mathrm{PB}$, phenobarbital; PBRU, phenobarbital-responsive enhancer unit; PROD, pentoxyresorufin $O$-dealkylase. 
wards nicotine, activate carcinogens and metabolize some drugs. Rat CYP2B isoforms are involved in the activation of arenes, arylamines and nitrosamines [2]. The metabolism of the tobacco-specific nitrosoamine 4-(methyl-nitrosoamino)-1-(3-pyridyl)-1-butanone (NNK) results in DNA adducts and methylation of guanine at the 60 position, thus leading to GC to AT transition in codon 12 and possibly Ki-ras oncogene activation, which seems to be one of the major causes of the high tumorigenicity of NNK in rat, mouse and hamster lungs [3].

CYP gene polymorphism and differences in the induction rate of some $\mathrm{P} 450$-linked activities are risk factors in several diseases, including tobacco smoke-dependent cancers in humans and experimental rodents [4]. Tobacco smoke contains about 4000 compounds, some of which may induce CYP2B, e.g. 1,1-di(p-chlorophenyl)-2,2,2-trichloroethane (DDT), 1,1di(p-chlorophenyl)-2,2-dichloroethylene - one of the DDT metabolites, as well as pyridine and acetone [5, 6]. When administered to pregnant females, lipophilic inducers of monooxygenases and their substrates usually cross the placenta to reach the fetal tissues. In the presence of effective fetal metabolic mechanisms these substrates may be converted to active metabolites that are able to damage DNA and produce mutations in fetal cells.

Between rat CYP2B1 and CYP2B2 proteins there is only a 13 amino acid difference, mostly in the C-flanking sequence of the protein (about $3 \%$ of the total CYP sequence), though $C Y P 2 B 1$ and $C Y P 2 B 2$ genes are nonallelic variants of the gene which contains nine exons [7]. Constitutively, the rat $C Y P 2 B 1$ and CYP2B2 genes exhibit extremely low basal expression [8]. PB raises 40-300-fold the expression of rat liver CYP2B enzymes [9] via a not fully understood, transcriptionally mediated molecular mechanism, probably through the CAR (constitutively activated receptor) [10]. This receptor dimerizes with RXR (retinoid X receptor), which has been shown to dimerize with some nuclear recep- tors [11]. The heterodimer binds to a PB-response element in the DNA, thereby activating the PB-dependent genes. The levels of CYP2B1 mRNA are generally higher than those of CYP2B2 mRNA, with the maximal gene transcription rate at $6 \mathrm{~h}$ after $\mathrm{PB}$ administration [9].

The level of cytochrome P450 is known to be age-related [12]. However, both CYP2B1 and CYP2B2 mRNA levels and their ratio remain unchanged with aging while their inducibility decreases after the 12 month of life [13]. Moreover, endocrine factors, such as glucocorticoids, sex and thyroid hormones, can affect the expression of PB-inducible P450 genes and may interfere with PB-related induction by triggering interactions between the nuclear factors [14].

The aim of this study was to detect the CYP2B1/2 protein in fetal and adult rat tissues and CYP2B6 protein in human placenta, and to evaluate the effects of gestation and tobacco smoke on their expression and on monooxygenase activities.

\section{MATERIALS AND METHODS}

Animals. The experiments were carried out on mature female Wistar rats weighing 200-220 g. The animals were divided into six groups of 3 (groups 1 and 2) or 15 (groups 3-6) rats, as follows:

(1) nonpregnant and (2) pregnant rats treated with phenobarbital at a daily i.p. dose of $80 \mathrm{mg} / \mathrm{kg} \mathrm{b.m}$. for 3 days before decapitation and on gestational days 18-20, respectively;

(3) control nonpregnant and (4) control pregnant rats kept under standard conditions;

(5) nonpregnant and (6) pregnant rats exposed to tobacco smoke at a concentration of $1500 \mathrm{mg} \mathrm{CO} / \mathrm{m}^{3}$.

Groups 1-4 were kept in standard conditions $\left(21^{\circ} \mathrm{C}, 55-60 \%\right.$ relative humidity, $12 /$ $12 \mathrm{~h}$ day-night cycle, fresh air). Groups 5 and 6 were placed in a toxicological chamber and ex- 
posed to tobacco smoke for 20 days ( $6 \mathrm{~h}$ a day, 5 days a week). The duration of exposure corresponded to the duration of pregnancy. Tobacco smoke was obtained from the non-filter cigarettes Popularne produced in Poland. Concentration of tobacco smoke was monitored indirectly with an Infralyt 1110/ 1210 gas analyzer which continuously measured the $\mathrm{CO}$ content (15\%). The oxygen level (about $21 \%$ ) was continuously monitored using a type 211 oxygen measuring device. The rate of air flow through the chamber was maintained at $0.6 \mathrm{~m}^{3} / \mathrm{h}$.

Human placentas. The placentas were from non-smoking (10 placentas), passive smoking (5 placentas) or active smoking (5 placentas) primiparas aged 20-30 years, admitted to the Department of Gynecology and Obstetrics, Central Teaching Hospital, Katowice. The pregnancies were normal, no drugs were given to the women, and all children were born transvaginally. Placentas obtained at night were immediately frozen and stored overnight at $-20^{\circ} \mathrm{C}$.

Preparation of microsomes. All rats were decapitated at the same time of day to avoid circadian changes in the activities of microsomal enzymes [15, 16]. Microsomal fractions were prepared by a modification of the method of Dallner [17]. Immediately after decapitation, adult, newborn and fetal livers, adult and newborn lungs, and adult brains, hearts and placentas were excised, rinsed several times in ice cold saline, cut into small pieces and homogenized in $2-5$ vol. of $0.25 \mathrm{M}$ sucrose containing $10 \mathrm{mM}$ Tris/ $\mathrm{HCl}(\mathrm{pH} 7.4$, $2{ }^{\circ} \mathrm{C}$ ) using a Potter-Elvehjem homogenizer with a Teflon piston.

The homogenate was centrifuged at 10000 $\times \boldsymbol{g}$ for $20 \mathrm{~min}$ and the resultant postmitochondrial supernatant was centrifuged at $105000 \times \boldsymbol{g}$ for $60 \mathrm{~min}$ to sediment microsomes. The microsomal pellet was suspended in $0.1 \mathrm{M}$ phosphate buffer containing $1 \mathrm{mM}$ EDTA, $1 \mathrm{mM}$ dithiothreitol and 20\% glycerol (pH 7.4). Concentration of the microsomal protein was determined by the method of Lowry et al. [18] with a bovine albumin solution as a standard.

A similar procedure was used to obtain microsomal fractions from human placentas, though the amount of homogenized tissue was much larger $(75 \mathrm{~g})$. The tissue to be homogenized was first carefully rinsed to remove blood and then it was cut in a knife homogenizer.

Gel electrophoresis and immunoblot analysis. Microsomal proteins were separated using SDS/polyacrylamide gel electrophoresis [19] and transferred onto a PVDF transfer membrane (Millipore). Cytochrome P450 2B1/2 and 2B6 proteins were identified with rabbit anti-rat polyclonal primary antibodies against both rat CYP2B1/2 and human CYP2B6 (Chemicon). The secondary antibody was goat anti-rabbit IgG conjugated with alkaline phosphatase (Sigma). The BCIP/NBT Liquid Substrate System (Sigma) was used to visualize alkaline phosphatase activity in immunoblots. Phenobarbital-induced microsomes were used as a positive control for CYP2B1/2 and 2B6. Samples contained the following amounts of microsomal protein: adult liver $-10 \mu \mathrm{g}$; adult lung $-40 \mu \mathrm{g}$; adult brain $-30 \mu \mathrm{g}$; adult heart $-20 \mu \mathrm{g}$; fetal liver $60 \mu \mathrm{g}$; newborn liver - $20 \mu \mathrm{g}$; newborn lung $50 \mu \mathrm{g}$; rat or human placenta $-70 \mu \mathrm{g}$; phenobarbital-induced adult rat liver $0.5-3 \mu \mathrm{g}$.

Immunoblots were quantified by the One-Dimensional Gel Analysis program (Scanalytics). Molecular mass of each protein in a band was also analyzed using Sigma Prestained SDS/PAGE Standard Solution.

Determination of cytochrome P450 and $\mathbf{b}_{5}$ levels. Cytochrome $\mathrm{P} 450$ and cytochrome $b_{5}$ levels were measured according to Omura \& Sato [20]. Millimolar absorption coefficients used for calculation were $91 \mathrm{mM}^{-1}$ $\mathrm{cm}^{-1}$ and $185 \mathrm{mM}^{-1} \mathrm{~cm}^{-1}$, respectively.

Enzyme assays. The activities of NADPHcytochrome P450 and NADH-cytochrome $b_{5}$ reductases were estimated spectrophotomet- 
rically by the method of Hodges \& Leonard [21] with the use of the molar absorption coefficient of $18.5 \mathrm{mM}^{-1} \mathrm{~cm}^{-1}$. The activity of pentoxyresorufin $O$-dealkylase (PROD), a highly sensitive and specific marker for CYP2B1/2, was measured by the fluorimetric method of Burke et al. [22]. The reactions were carried out at $37^{\circ} \mathrm{C}$ and the reaction rate was determined by measuring the fluorescence of the reaction mixture using a PerkinElmer model MPF44A spectrofluorimeter $\left(\lambda_{\mathrm{ex}}\right.$ $=557 \mathrm{~nm}$ and $\lambda_{\text {em }}=587 \mathrm{~nm}$ ).

Determination of nicotine and cotinine levels. The efficacy of exposure was assessed by measuring the nicotine and cotinine (a nicotine metabolite) level in urine. Samples of morning urine $(10 \mathrm{ml})$ were collected from all patients on the day of delivery. Urine from adult female rats was collected for $24 \mathrm{~h}$ before decapitation. All urine samples were frozen and stored until assayed. Nicotine and cotinine levels were assessed by high-pressure liquid chromatography (HPLC) [23].

Statistical analysis. Enzymatic activities were the arithmetic mean \pm S.D. of three adult rats (liver); or five human placentas; or three pools of 15-20 rat foetuses or newborns each (fetal and newborn tissues); or three pools of 10-12 placentas each; or (for extrahepatic tissues) three pools of five adult rats each. Statistical significance was estimated with Student's $t$-test $(P<0.05)$.

\section{RESULTS}

\section{Nicotine and cotinine levels}

Urine nicotine and cotinine were undetectable in untreated nonpregnant and pregnant rats. In tobacco smoke exposed nonpregnant rats nicotine and cotinine levels were $3.64 \pm$ 2.68 and $41.89 \pm 8.78 \mu \mathrm{g} / 24 \mathrm{~h}$, respectively. In exposed pregnant rats nicotine and cotinine levels were $0.65 \pm 0.28$ and $36.56 \pm 6.56 \mu \mathrm{g} / 24$ $h$, respectively. The differences between non- pregnant and pregnant rats were statistically insignificant.

In pregnant women, urine cotinine level was undetectable in non-smokers; it was 0$0.033 \mu \mathrm{g} / \mathrm{ml}$ in passive smokers and 0.140 $0.553 \mu \mathrm{g} / \mathrm{ml}$ in active smokers (to 10 cigarettes per day).

Effects of tobacco smoke on drug metabolizing enzymes in fetal and newborn rat tissues

Hepatic or pulmonary levels of total P450 and cytochrome $b_{5}$, the expression of CYP2B1/2 protein and CYP2B1/2-dependent PROD activity were undetectable in untreated fetuses and newborns (not shown).

Rat fetuses from females exposed to tobacco smoke for 20 days showed a faint band of liver microsome CYP2B1/2 at day 21 of gestation and rat newborns expressed CYP2B1/2 in their livers and lungs (Fig. 1A and C). The increased CYP2B1/2 protein expression in the tobacco smoke-exposed newborns was accompanied by a slight increase in liver and lung PROD activities (Table 1), but not by an increase in the activity of cytochrome P450- or cytochrome $b_{5}-$ co-operating reductases (Table 2).

\section{Effects of tobacco smoke on drug metaboliz- ing enzymes in rat and human placenta}

CYP2B1/2 protein expression was undetectable in microsomes from the control and tobacco smoke-exposed rat placentas. The blots did not indicated presence of CYP2B6 protein in human placentas from pregnant non-smokers, passive smokers and active smokers (not shown). Similarly, total P450 and cytochrome $b_{5}$, and PROD activity were undetectable in controls and exposed groups in rat or human placentas. Exposure to tobacco smoke did not cause any statistically significant changes in the activity of NADPH-cytochrome P450 or $\mathrm{NADH}$-cytochrome $b_{5}$ reductases in the rat or human placenta (Tables 1 and 2). 


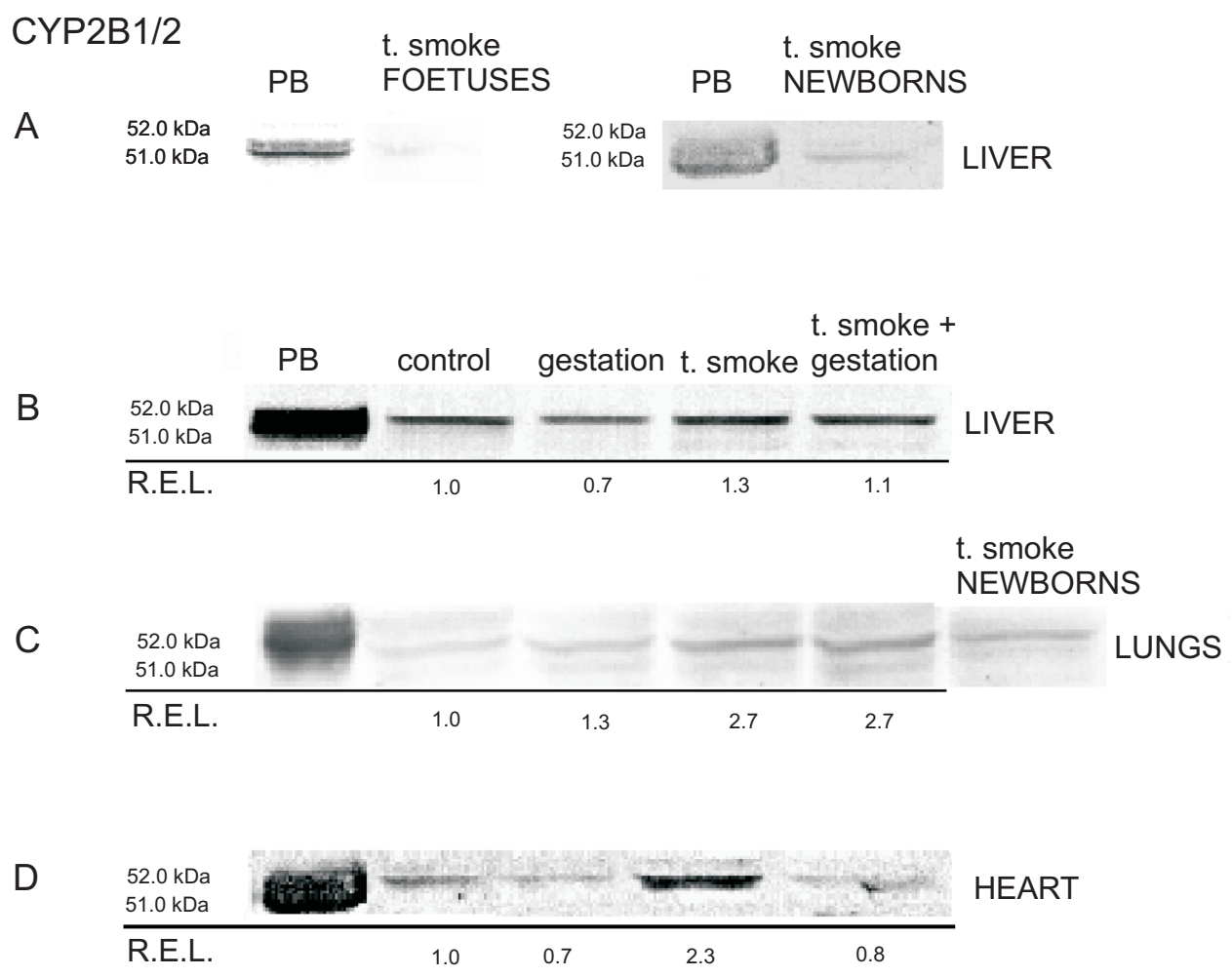

Figure 1. Immunodetection of CYP2B1/2 protein in rat (A) fetal and newborn liver, (C) newborn lungs; and (B-D) adult liver, lungs and heart, respectively.

For Western blot analysis, rat liver microsomes were prepared from individual adult female rats or 15-20 foetuses or newborns; rat placenta microsomes were prepared from pools of 10-12 placentas; human microsomes - from individual placentas. Rat lung, brain and heart microsomes were prepared from pools of tissues from five adult rats; or (in the case of lungs) 20 newborns. Western blot analyses were performed in duplicate with similar results. Positive blots are presented. PB, hepatic microsomes from phenobarbital-induced rats ( $80 \mathrm{mg} / \mathrm{kg}$ per 3 days); control, non pregnant rats; gestation, pregnant rats at day 21 ; t. smoke, rats exposed to tobacco smoke $\left(1500 \mathrm{mg} \mathrm{CO} / \mathrm{m}^{3} \mathrm{per}\right.$ 20 days). Immunoblots from adult rats were quantified by densitometry. R.E.L., relative expression level.

\section{Effects of pregnancy on drug metabolizing enzymes in unexposed rats}

The mechanisms regulating $\mathrm{P} 450$ s in pregnancy inhibit basal CYP2B1/2 expression in liver $(30 \%)$ and heart (30\%) but not in lungs (Fig. 1B-D). The decreased hepatic level of CYP2B1/2 was not accompanied by a statistically significant decrease in PROD activity whereas the increased pulmonary level of CYP2B1/2 protein (30\%) was accompanied by unchanged PROD activity in controls (Table 1). Pregnancy did not affect either total $\mathrm{P} 450$ and cytochrome $b_{5}$ contents, or the activities of co-operating reductases in all the investigated organs (Table 2).
Effects of tobacco smoke on drug metabolizing enzymes in nonpregnant and pregnant rats

In adult exposed rats, total $\mathrm{P} 450$ content in liver microsomes was unchanged (Table 2) despite an increase in CYP2B1/2 protein expression $(52.0 \mathrm{kDa})$ both in nonpregnant $(30 \%)$ and pregnant (40\%) females (Fig. 1B), which correlated with changes in PROD activity $(P<0.05)$ in nonpregnant females (Table 1$)$. Tobacco smoke produced no significant changes in hepatic NADH-cytochrome $b_{5}$ reductase activity and cytochrome $b_{5}$ levels. Exposure for 20-days to tobacco smoke (1500 $\mathrm{mg} \mathrm{CO} / \mathrm{m}^{3}$ ) resulted in a significant increase 
in hepatic NADPH-P450 reductase activity in both nonpregnant and pregnant animals (Table 2).

Tobacco smoke strongly induced lung CYP2B1/2 protein $(51.0 \mathrm{kDa})$ in nonpregnant and pregnant female rats (Fig. 1C); this induction was not accompanied by an increase in PROD activity and total P450 content (Table 1 ). Cytochrome $b_{5}$ content (practically undetectable) and activities of both reductases were not changed by tobacco smoke (Table 2).
CYP2B1/2 expression at day 21 of gestation, while $\mathrm{PB}$ induced a very faint band of microsomal protein. In other studies on rats, PB transplacentally induced CYP2B1/2 mRNA as early as at gestation day 15 [26]. In lungs of untreated rats, CYP2B proteins and NADPH-cytochrome $\mathrm{P} 450$ reductase were detected immunohistochemically at day 4 of postnatal life in Clara cells, as early as at day 20 of gestation in endothelial cells, and from postnatal day 7 in type II alveolar cells. Also at

\section{Table 1. Effects of pregnancy and tobacco smoke on pentoxyresorufin $O$-dealkylase in rat tissues.}

The specific activities are expressed in pmoles/min per mg of microsomal protein. CYP2B1/2-dependent PROD activity was undetectable in livers of untreated and exposed rat foetuses, rat and human placenta, and adult rat brain and heart (not shown).

\begin{tabular}{lcccc}
\hline & Nonpregnant rats & Pregnant rats & $\begin{array}{c}\text { Nonpregnant/ } \\
\text { tobacco smoker }\end{array}$ & $\begin{array}{c}\text { Pregnant/ } \\
\text { tobacco smoker }\end{array}$ \\
\hline Adult liver & $6.00 \pm 0.19$ & $4.48 \pm 0.77$ & $11.5 \pm 0.97^{*}$ & $5.94 \pm 1.11$ \\
Adult lungs & $3.02 \pm 0.39$ & $3.05 \pm 0.42$ & $3.46 \pm 0.71$ & $4.18 \pm 0.08$ \\
Newborn liver & N.D. & - & $0.62 \pm 0.20$ & - \\
Newborn lungs & N.D. & - & $0.82 \pm 0.35$ & - \\
\hline
\end{tabular}

*Statistically significant compared with nonpregnant and pregnant exposed rats $(P<0.05)$. N.D., not detected.

No CYP2B1/2 protein in the adult brain nor any PROD activity expression, total $\mathrm{P} 450$ or cytochrome $b_{5}$ were detected in the brain and heart of nonpregnant and pregnant rats in the control and exposed groups (not shown). We detected CYP2B1/2 protein in the hearts of nonpregnant and pregnant female rats (Fig. 1D). Tobacco smoke induced NADPH-cytochrome $\mathrm{P} 450$ and NADH-cytochrome $b_{5}$ reductase activities, and $\mathrm{CYP} 2 \mathrm{~B} 1 / 2$ protein expression in both groups of rats, though the induction was weaker in pregnant rats.

\section{DISCUSSION}

The expression and monooxygenase activity of fetal microsomal CYP2B1/2 are very low or undetectable in rodents, but they increase rapidly soon after birth [24]. In our former study [25], fetal liver showed no constitutive day 7 of postnatal life PROD activity was detected in liver and lung homogenates [27, 28]. In mice and hamsters, CYP2B isoforms were detected in fetal liver and lung (cf. [25]).

In this study, we have provided quite convincing evidence that CYP2B1/B2 isoforms are expressed in newborn rat liver and lungs at biologically significant levels, which make possible the metabolism of pentoxyresorufin, a specific substrate for CYP2B1/2. It also seems that, on the last day of pregnancy, regulatory gene mechanisms are already present in the fetal liver, allowing the fetal CYP2B isoenzymes to be induced in response to xenobiotics. The inductory effect of tobacco smoke was achieved at its high concentration (1500 $\mathrm{mg} \mathrm{CO} / \mathrm{m}^{3}$ ). In a study by Gebremichael et al. [28] tobacco smoke induced neither pulmonary nor hepatic PROD activities; monooxygenase CYP2B1 activities, both basal and that influenced by diluted side-stream tobacco 
smoke, were detected in the lung and liver as late as between 7 and 100 days post partum.

The rat $C Y P 2 B 1$ and $C Y P 2 B 2$ genes are often considered as a single gene termed criptionally inactive in untreated rats [7]. PB induced the two mRNAs in such a way that the level of liver CYP2B1 mRNA was 5 times higher than that of CYP2B2 mRNA, and that

Table 2. Effects of pregnancy and tobacco smoke on cytochrome P450 and $b_{5}$ levels and on activities of NADPH-cytochrome $\mathrm{P} 450$ and NADH-cytochrome $b_{5}$ reductase in rat tissues and human placenta

\begin{tabular}{|c|c|c|c|c|c|}
\hline & Rat organ & Nonpregnant & Pregnant & $\begin{array}{l}\text { Nonpregnant/ } \\
\text { tobacco smoker }\end{array}$ & $\begin{array}{l}\text { Pregnant/ } \\
\text { tobacco smoker }\end{array}$ \\
\hline \multirow{9}{*}{$\begin{array}{l}\text { NADPH-cyto- } \\
\text { chrome P450 } \\
\text { reductase } \\
\mu \mathrm{mol} / \mathrm{min} \\
\mathrm{per} \mathrm{mg}\end{array}$} & adult liver & $0.061 \pm 0.004$ & $0.060 \pm 0.002$ & $0.071 \pm 0.004^{*}$ & $0.073 \pm 0.006^{* *}$ \\
\hline & newborn liver & $0.014 \pm 0.002$ & - & $0.020 \pm 0.002$ & - \\
\hline & fetal liver & $0.011 \pm 0.003$ & - & $0.014 \pm 0.001$ & - \\
\hline & adult lungs & $0.039 \pm 0.004$ & $0.041 \pm 0.002$ & $0.037 \pm 0.003$ & $0.032 \pm 0.002$ \\
\hline & newborn lungs & $0.038 \pm 0.004$ & - & $0.048 \pm 0.003$ & - \\
\hline & adult heart & $0.007 \pm 0.000$ & $0.006 \pm 0.001$ & $0.020 \pm 0.003^{*}$ & $0.014 \pm 0.001$ \\
\hline & adult brain & $0.048 \pm 0.010$ & $0.059 \pm 0.001$ & $0.051 \pm 0.001$ & $0.054 \pm 0.001$ \\
\hline & placenta & - & $0.028 \pm 0.003$ & - & $0.029 \pm 0.004$ \\
\hline & Human placenta & - & $0.036 \pm 0.014$ & - & $0.037 \pm 0.014$ \\
\hline \multirow{11}{*}{$\begin{array}{l}\text { NADH-cyto- } \\
\text { chrome } \boldsymbol{b}_{\mathbf{5}} \\
\text { reductase } \\
\boldsymbol{\mu} \mathrm{mol} / \mathrm{min} \\
\mathrm{per} \mathrm{mg}\end{array}$} & Rat organ & & & & \\
\hline & adult liver & $0.58 \pm 0.14$ & $0.60 \pm 0.11$ & $0.46 \pm 0.07$ & $0.54 \pm 0.15$ \\
\hline & newborn liver & $0.039 \pm 0.004$ & - & $0.041 \pm 0.005$ & - \\
\hline & fetal liver & $0.034 \pm 0.005$ & - & $0.042 \pm 0.004$ & - \\
\hline & adult lungs & $0.117 \pm 0.004$ & $0.104 \pm 0.019$ & $0.110 \pm 0.018$ & $0.094 \pm 0.011$ \\
\hline & newborn lungs & $0.109 \pm 0.003$ & - & $0.104 \pm 0.015$ & - \\
\hline & adult heart & $0.048 \pm 0.026$ & $0.064 \pm 0.004$ & $0.127 \pm 0.015^{*}$ & $0.146 \pm 0.001^{* *}$ \\
\hline & adult brain & $0.076 \pm 0.006$ & $0.081 \pm 0.007$ & $0.078 \pm 0.002$ & $0.077 \pm 0.004$ \\
\hline & placenta & - & $0.167 \pm 0.060$ & - & $0.119 \pm 0.021$ \\
\hline & Human placenta & - & $0.049 \pm 0.015$ & - & $0.041 \pm 0.011$ \\
\hline & Rat organ & & & & \\
\hline \multirow{2}{*}{$\begin{array}{l}\text { Cytochrome } \\
\mathbf{P 4 5 0} \\
\mathrm{nmol} / \mathrm{mg}\end{array}$} & adult liver & $0.49 \pm 0.01$ & $0.45 \pm 0.03$ & $0.61 \pm 0.05$ & $0.50 \pm 0.04$ \\
\hline & adult lungs & $0.18 \pm 0.05$ & $0.21 \pm 0.08$ & $0.31 \pm 0.15$ & $0.12 \pm 0.04$ \\
\hline $\begin{array}{l}\text { Cytochrome } \boldsymbol{b}_{\mathbf{5}} \\
\mathrm{nmol} / \mathrm{mg}\end{array}$ & adult liver & $0.38 \pm 0.02$ & $0.37 \pm 0.04$ & $0.35 \pm 0.02$ & $0.35 \pm 0.04$ \\
\hline
\end{tabular}

CYP2B1/2 because molecular mass of their protein products are similar, the nucleotide sequences of the proximal promoter and sequences $5^{\prime}$ distal to the proximal promoter (phenobarbital-responsive enhancer unit PBRU) in CYP2B1 and 2B2 genes are almost identical, and responses of these genes to $\mathrm{PB}$ are very similar [29]. On the other hand, there are significant differences in tissue-specific expression between CYP2B1 (51.0 kDa) and CYP2B2 (52.0 kDa). In liver, the $2 B 2$ gene was constitutively expressed, while $2 B 1$ was trans- of CYP2B1 protein was twice as high as of CYP2B2 protein [25, 30]. In lungs CYP2B2 is not expressed, while CYP2B1 is expressed constitutively and is not at all or only slightly induced by PB [25, 29]. In our former study, CYP2B1 was about 60 -fold less inducible in the lung than in the liver [25]. In this study, PB-induced expression of the liver CYP2B1/2 protein as two closely positioned bands, and differences in tobacco smoke-induced and tissue-specific expression between CYP2B1 and CYP2B2 are visible. The organ-dependent dif- 
ferences between CYP2B1 and CYP2B2 expression result probably from a single nucleotide sequence difference between the $C Y P 2 B 1$ and CYP2B2 5'-flanking regions in the similarly positioned PBRU. It seems likely that the expression of an individual $C Y P 2 B$ PBRU is turned on by transcription factors that recognize that sequence difference [29, 31].

Changes in the total P450 content do not reflect changes in the expression of individual $\mathrm{P} 450$ isoforms [6]. Cytochromes $\mathrm{P} 450$ cooperate with NADPH-cytochrome $\mathrm{P} 450$ reductase and also with the NADH-cytochrome $b_{5}$ reductase-cytochrome $b_{5}$ electron transport chain, which may largely modify the activity of P450s [21]. In adult Wistar rats exposed to tobacco smoke for 5 days, liver cytochrome $\mathrm{P} 450$ and NADPH-P450 reductase were unchanged, whereas cytochrome $b_{5}$ was significantly increased and CYP2B1 was slightly increased [5]. Wardlaw et al. [32] also observed increased liver CYP2B1/2 levels in 2-month old rats exposed to mainstream cigarette smoke. Similarly, in some other studies tobacco smoke did not alter the total P450 content, although it induced CYP isoforms, including CYP2B1 (cf. [5]). All these studies, as well as the results of the present study concerning adult female Wistar rats have confirmed that tobacco smoke induces CYP2B1/2 in the nonpregnant rat liver in such a way that the total P450 content is not changed, while the related monooxygenase activity is increased. We found that, in exposed rats, the hepatic NADPH-P450 reductase activity was significantly increased, but NADH-cytochrome $b_{5}$ reductase activity and cytochrome $b_{5}$ levels were unchanged; the latter observation disagrees with Kawamoto's finding [5].

On the other hand, in adult mice, total P450 and $b_{5}$ levels decreased by about one third as early as 4 days after exposure to tobacco smoke. At the same time liver CYP2B subfamily expression decreased, while PROD activity increased reaching the maximum after 8 days of exposure. Total lung CYP2B expression was highly induced, the degree of this in- duction increasing with the time of exposure [6]. This inverse relationship between CYP2B expression and PROD activity observed at the cytochrome subfamily level in the mouse liver appears to be inconsistent with what was found in rats in the above-mentioned studies. In fact, studies of individual CYP2B isoforms showed that the expression of mouse Cyp2b10 mRNA (which corresponds to rat 2B1/2) increased in the livers of most of tobacco smokeinhaled groups and remained stable in lung microsomes [6]. Thus, in rats and mice, liver and lung $2 \mathrm{~B}$ isoforms (see below) similarly responded to the same inducer, indicating that the structure of the inducer-responsive enhancer regions of $C Y P 2 B$ genes may play a crucial role in the regulation of expression of these genes. In the mouse Cyp2b10 gene, the 51-bp PBRU region containing critical motifs for binding nuclear receptor and nuclear factor 1 is almost identical with the corresponding region of the rat CYP2B2 gene [31]. The 51-bp PBRU region of the mouse Cyp2b9 gene exhibited many mutations, which abolished the inducer-dependent activity of the gene and made Cyp2b9 mRNA undetectable either in the liver or lung microsomes.

While studying the effect of tobacco smoke on CYP2B expression in the respiratory system, Wardlaw et al. [32] observed that, in adult male rats, CYP2B1/2 content remained unchanged in the lung, and was decreased in nasal tissues after 2 and 8 weeks of tobacco smoke exposure. This latter decline was supported by a decline in PROD activity. In lungs PROD activity was also decreased and did not correlate so strongly with the CYP2B1/2 content. In this study, the tobacco smoke dependent induction of lung CYP2B1/2 protein in nonpregnant and pregnant females was not accompanied by an increase in PROD activity and total $\mathrm{P} 450$ content. The unchanged activity of PROD may partly be explained by undetectable cytochrome $b_{5}$ level and unchanged reductases activity. Thus, in the lungs of rat females, the inductory effect of tobacco smoke on CYP2B1/2 was, in contrast to the liver, not 
reflected by increased monooxygenase activity. This difference between the response of the two organs could be due to different patterns of expression of CYP2B isoforms and from tobacco smoke-related differences in the reductase activities. It is noteworthy that lung CYP2B1/2 protein was induced in a sex-dependent manner: CYP2B1/2 expression was induced by tobacco smoke in female rats but not in males [32].

There is some question whether P450 can fulfill a catalytic function in the mammalian heart since its constitutive levels are very low. In rodents, CYP1A1 with low NADPH-P450 reductase activity and an immunoreactive CYP2B4 protein have been found in the endothelium and cardiac microsomes, respectively [33, 34]. We detected CYP2B1/2 protein in the hearts of nonpregnant and pregnant females and we found that tobacco smoke induced this isoform, especially in nonpregnant rats. Matsusue et al. [35] observed that the role of cytochrome $b_{5}$ varied depending on the CYP isoform and that the rates of some hydroxylations linked with CYP2B1 were increased in vitro in the presence of cytochrome $b_{5}$ compared to the activities of CYP1A1. The absence of 2B1/2-dependent PROD monooxygenase in the heart may in part result from cytochrome $b_{5}$ deficiency and low activities of $\mathrm{NADPH}-\mathrm{P} 450$ and NADH- $b_{5}$ reductases, which are another critical factors for the function of CYP2B. These results have provided quite convincing evidence that if CYP2B1/2 isoforms and NADPH-P450 and NADH- $b_{5}$ reductases were expressed and induced by tobacco smoke in rat heart, their levels would be toxicologically insignificant.

The rat, brain and placenta do not seem to play a significant role in the metabolism of CYP2B1/2 substrates from tobacco smoke, as in those organs CYP2B1/2 expression is undetectable. In human placenta, PB-dependent monooxygenases are probably not present since (i) CYP2B6 mRNA was absent in both first-trimester and full-term human placentas from nonsmoking and smoking mothers [36,
37], (ii) there were neither antigenic determinants of CYP2B6 protein nor CYP2B6 response to the specific substrates [38]. In the present study, we have confirmed the abovementioned findings at the protein level. The facts that (i) CYP2B1/2 and PROD can be induced in the maternal liver, (ii) CYP2B1/2 can be induced in some extrahepatic organs (lungs and heart), and that (iii) the placenta and fetal tissues do not express these activities, indicate that the main risk factors for the foetus exposed to tobacco smoke arises from active products of CYP2B1/2-dependent reactions generated in the maternal liver and flowing in blood to the foetus.

$\mathrm{P} 450$ isoforms that are susceptible to PB induction are differently regulated by endogenous hormonal factors. The effect of estradiol on liver CYP2C is indirect; i.e., estradiol acts on the hypothalamic-pituitary axis, thus being responsible for the sex-specific effects of the growth hormone secretory pattern [39]. It also seems that endogenous steroids regulate the synthesis of CYP2B1/2 mRNA and protein. Tobacco smoke is known to interfere with cellular signalling as it greatly enhances 2 -hydroxylation of $\beta$-estradiol, which leads to decrease a level of estrogen, an active ligand. Exposure to tobacco smoke components would thus decrease the number of functional estrogen molecules participating in ligandmodulated transcription. These findings suggest that the estrogen response in female smokers may be reduced [40].

In pregnancy, progesterone or its metabolites seem to play a greater role than estrogens in the regulation of CYP expression. It has been shown that high plasma levels of both progesterone and its metabolites are directly linked to depressed hepatic drug metabolism (cf. [41]). The pregnancy-related reduction in drug metabolism and in vitro treatment with some progesterone derivatives resulted in a significant reduction in the CYP2B1/2-dependent 16-hydroxylation of progesterone. These changes were accompanied by a significantly decreased ratio of 
phosphatidylcholine to phosphatidylethanolamine, the latter of which stimulates the hydroxylation of some xenobiotics. The decrease in total $\mathrm{P} 450$ content and inhibition of the P450-dependent metabolism of xenobiotics observed in pregnancy [42], may reduce the risk associated with the generation of active metabolites. Further studies revealed that pregnancy (like other physiological factors such as age, sex and lactation) is associated with changes in the rat liver pattern of P450 isoforms; for example, CYP2E1 and CYP2C11/6 levels decrease slightly in pregnancy, and CYP1A1/2, and CYP2B1/2 levels remain unchanged [43]. In a study by Borlakoglu et al. [41] CYP2C6 and CYP3A1 protein levels were unchanged, while CYP1A1/2, CYP2A1, CYP2B1/2, and CYP4A1 protein levels were undetectable in hepatic microsomes from pregnant and lactating rats, although the corresponding mRNAs were detected by Northern blot analysis. The amounts of these mRNAs differed; CYP2B1 mRNA was reduced to $50 \%$. In pregnant hamsters, compared with nonpregnant female hamsters, the hepatic levels of CYP2B1 mRNA and protein, but not of CYP2B2, decreased, while the pulmonary level of CYP2B1 increased at the mRNA level and was not affected by pregnancy at the protein level [3].

In the present study, pregnancy was associated with decreased levels of CYP2B1/2 protein in liver and heart, but not in lung in control and tobacco smoke-treated rats. In contrast to the results of Kawamoto et al. [5] CYP2B1/2 was detectable in liver; however, we loaded 3.3-fold more protein per well. The decreased hepatic levels of CYP2B1/2 were accompanied by decreased PROD activity in tobacco smoke-treated pregnant females. One can suppose that the effects of metabolic activation of CYP2B1/2 substrates in these organs will be reduced in pregnancy. The results of the present study have demonstrated that the hepatic and cardiac patterns of CYP2B1/2 expression are similar and that they are different from the pulmonary pattern. The pro- portion of expressions of CYP2B1 to CYP2B2 gene may underlie differences in the regulation of the activity of these two cytochromes in the organs studied.

\section{R E F E R E N C ES}

1. Gonzalez, F. \& Gelboin, H. (1994) Role of human cytochromes $\mathrm{P} 450$ in the metabolic activation of chemical carcinogens and toxins. Drug Metab. Rev. 26, 165-183.

2. Mori, Y., Iimura, K., Furukawa, F., Nishikawa, A., Takahashi, M. \& Konishi, Y. (1995) Effect of cigarette smoke on the mutagenic activation of various carcinogens in hamster. Mutat. Res. 346, 1-8.

3. Miller, M., Warner, S., Jorquera, R., Castonguay, A. \& Schüller, H. (1992) Expression of the cytochrome $\mathrm{P} 4502 \mathrm{E}$ and $2 \mathrm{~B}$ gene families in the lungs and livers of nonpregnant, pregnant, and fetal hamsters. Biochem. Pharmacol. 44, 797-803.

4. Whitlock, J. \& Denison, M. (1995) Induction of cytochrome P450 enzymes that metabolize xenobiotics; in Cytochrome P450: Structure, Mechanisms and Biochemistry (Ortiz de Montellano P., ed.) pp. 367-390, Plenum Press, New York and London.

5. Kawamoto, T., Yoshikawa, M., Matsuno, K., Kayama, F., Oyama, T., Arashidani, K. \& Kodama, Y. (1993) Effect of side-stream cigarette smoke on the hepatic cytochrome $\mathrm{P} 450$. Arch. Environ. Contam. Toxicol. 25, 255-259.

6. Villard, P., Seree, E., Re, J., DeMeo, M., Barra, Y., Attolini, L., Dumenil, G., Catalin, J., Durand, A. \& Lacarelle, B. (1998) Effects of tobacco smoke on the gene expression of the CYP1a, CYP2b, CYP2e and CYP3a subfamilies in mouse liver and lung: Relation to single strand breaks of DNA. Toxicol Appl. Pharmacol. 148, 195-204. 
7. Gonzalez, F. (1989) The molecular biology of cytochrome P450s. Pharmacol. Rev. 40, 243-288.

8. de Montellano, O. (1995) Cytochrome P450. Structure, Mechanism, and Biochemistry (Ortiz de Montellano P., ed.) p. 608, Plenum Press, New York and London.

9. Omiecinski, C., Walz, F. \& Vlasuk, G. (1985) Phenobarbital induction of rat liver cytochromes P-450b and P-450e. Quantitation of specific RNAs by hybridization to synthetic oligodeoxyribonucleotide probes. J. Biol. Chem. 260, 3247-3250.

10. Honkakoski, P., Zelko, I., Sueyoshi, T. \& Negishi, M. (1998) The nuclear orphan receptor CAR-retinoid $\mathrm{X}$ receptor heterodimer activates the phenobarbital-responsive enhancer module of the CYP2B gene. Mol. Cell. Biol. 18, $5652-5658$.

11. Enmrak, E. \& Gustafsson, J. (1996) Orphan nuclear receptors - the first eight years. Mol. Endocrinol. 10, 1293-1307.

12. Czekaj, P. \& Plewka, A. (1990) Porównanie aktywności wątrobowego i nerkowego układu oksydaz o funkcji mieszanej (MFO) w różnych okresach życia pozapłodowego szczurów. Folia Med. Cracov. XXXI, 3, 225-236 (in Polish).

13. Horbach, J., van Asten, J. \& van Bezooijen, C. (1990) The influence of ageing on the induction of the mRNAs of rat liver cytochromes P450IIB1 and P450IIB2. Biochem. Pharmacol. 40, 529-533.

14. Honkakoski, P. \& Negishi, M. (1997) Characterization of a phenobarbital-responsive enhancer module in mouse $\mathrm{P} 450$ Cyp2b10 gene. J. Biol. Chem. 272, 14943-14949.

15. Czekaj, P., Plewka, A., Krzyżak, G., Plewka, D. \& Kamiński, M. (1989) Studies on circadian rhythm of microsomal ingredients of transport electron chains in young rats. Rev. Roum. Biochim. 26, 19-26.
16. Czekaj, P., Plewka, A., Kamiński, M., Nowaczyk-Dura, G., Pawlicki, K. \& Wielgus-Serafińska, E. (1994) Daily and circadian rhythms in the activity of mixed function oxidases system in rats of different age. Biol. Rhythm Res. 25, 1-9.

17. Dallner, G. (1974) Isolation of rough and smooth microsomes - general. Methods Enzymol. 32, 191-215.

18. Lowry, O., Rosebrough, N., Farr, A. \& Randall, R. (1951) Protein measurement with the Folin phenol reagent. J. Biol. Chem. 193, 265-275.

19. Laemmli, U. (1970) Cleavage of structural proteins during the assembly of the head of bacteriophage T4. Nature 227, 680-685.

20. Omura, T. \& Sato, R. (1964) The carbon monoxide-binding pigment of liver microsomes. I. Evidence for its hemoprotein nature. J. Biol. Chem. 239, 2370-2378.

21. Hodges, T. \& Leonard, R. (1974) Purification of a plasma membrane-bound adenosine triphosphatase from plant roots. Methods Enzymol. 32, 392-406.

22. Burke, M., Thompson, S., Elcombe, C., Halpert, J., Haaparanta, T. \& Mayer, R. (1985) Ethoxy-, pentoxy- and benzyloxyphenoxazones and homologues: A series of substrates to distinguish between different induced cytochromes P-450. Biochem. Pharmacol. 34, 33373345 .

23. Perkins, S., Livesey, J., Escares, E., Belcher, J. \& Dudley, D. (1991) High-performance liquid-chromatographic method compared with a modified radioimmunoassay of cotinine in plasma. Clin. Chem. 37, 1989-1993.

24. Cresteil, T., Beaune, C., Celier, C., Leroux, J., Guengerich, F. (1986) Cytochrome P450 isoenzyme content and monooxygenase activities in rat liver: Effect of ontogenesis and pretreatment by phenobarbital and 3-methycholanthrene. J. Pharmacol. Exp. Ther. 236, 269276. 
25. Czekaj, P., Wiaderkiewicz, A. \& Wiaderkiewicz, R. (2000) Immunodetection of cytochrome P450 isoforms in fetus and adult female Wistar rats. Acta Pol. Toxicol. 1, 17-31.

26. Omiecinski, C., Hassett, C., Costa, P. (1990) Developmental expression and in situ localization of the phenobarbital-inducible rat hepatic mRNAs for cytochromes CYP2B1, CYP2B2, CYP2C6, and CYP3A1. Mol. Pharmacol. 38, $462-470$.

27. Ji, C., Cardoso, W., Gebremichael, A., Philpot, R., Buckpitt, A., Plopper, C. \& Pinkerton, K. (1995) Pulmonary cytochrome P-450 monooxygenase system and Clara cell differentiation in rats. Am. J. Physiol. 269, L394-L402.

28. Gebremichael, A., Chang, A., Buckpitt, A., Plopper, C. \& Pinkerton, K. (1995) Postnatal development of cytochrome P4501A1 and 2B1 in rat lung and liver: Effect of aged and diluted sidestream cigarette smoke. Toxicol. Appl. Pharmacol. 135, 246-253.

29. Stoltz, C., Vachon, M.-H., Trottier, E., Dubois, S., Paquet, Y. \& Anderson, A. (1998) The CYP2B2 phenobarbital response unit contains an accessory factor element and a putative glucocorticoid response element essential for conferring maximal phenobarbital responsiveness. J. Biol. Chem. 273, 8528-8536.

30. Hardwick, J., Gonzalez, F. \& Kasper, C. (1983) Transcriptional regulation of rat liver epoxide hydratase, NADPH-cytochrome P-450 oxidoreductase, and cytochrome $\mathrm{P}-450 \mathrm{~b}$ genes by phenobarbital. J. Biol. Chem. 258, 80818085 .

31. Honkakoski, P., Moore, R., Washburn, K. \& Negishi, M. (1998) Activation by diverse xenochemicals of the 51-base pair phenobarbital-responsive enhancer module in the Cyp2b10 gene. Mol. Pharmacol. 53, 597-601.

32. Wardlaw, S., Nikula, K., Kracko, D., Finch, G., Thornton-Manning, J. \& Dahl, A. (1998) Effect of cigarette smoke on CYP1A1, CYP1A2 and
CYP2B1/2 of nasal mucosae in F344 rats. Carcinogenesis 19, 655-662.

33. Annas, A. \& Brittebo, E. (1998) Localization of cytochrome P4501A1 and covalent binding of a mutagenic heterocyclic amine in blood vessel endothelia of rodents. Toxicology 129, $145-156$.

34. Serabjit-Singh, C., Nisho, S., Philpot, R. \& Plopper, C. (1988) The distrubution of cytochrome P-450 monooxygenase in cells of rabbit lung: An ultrastructural immunocytochemical characterization. Mol. Pharmacol. 33, 279-289.

35. Matsusue, K., Ariyoshi, N., Oguri, K., Koga, N. \& Yoshimura, H. (1996) Role of cytochrome $b_{5}$ in the oxidative metabolism of polychlorinated biphenyls catalyzed by cytochrome P450. Xenobiotica 26, 405-414.

36. Hakkola, J., Pasanen, M., Hukkanen, J., Pelkonen, O., Maenpaa, J., Edwards, R., Boobis, A. \& Raunio, H. (1996) Expression of xenobiotic-metabolizing cytochrome P450 forms in human full-term placenta. Biochem. Pharmacol. 51, 403-411.

37. Hakkola, J., Raunio, H., Purkunen, R., Pelkonen, O., Saarikoski, S., Cresteil, T. \& Pasanen, M. (1996) Detection of cytochrome P450 gene expression in human placenta in first trimester of pregnancy. Biochem. Pharmacol. 52, 379-383.

38. Pasanen, M. (1994) The expression and environmental regulation of $\mathrm{P} 450$ enzymes in human placenta. Crit. Rev. Toxicol. 24, 211-229.

39. Waxman, D. \& Chang, T. (1995) Hormonal regulation of liver cytochrome P450 enzymes; in Cytochrome P450: Structure, Mechanisms and Biochemistry (Ortiz de Montellano, P., ed.) pp. 391-442, Plenum Press, New York and London.

40. Nebert, D. (1994) Drug-metabolizing enzymes in ligand-modulated transcription. Biochem. Pharmacol. 47, 25-37. 
41. Borlakoglu, J., Scott, A., Henderson, C. \& Wolf, C. (1993) Alterations in rat hepatic drug metabolism during pregnancy and lactation. Biochem. Pharmacol. 46, 29-36.

42. Lambert, G., Lietz, H. \& Kotake, A. (1987) Effects of pregnancy on the cytochrome P-450 system in mice. Biochem. Pharmacol. 36, $1965-1971$.
43. Nakajima, T., Wang, R.-S., Katakura, Y., Kishi, R., Elovaara, E., Park, S., Gelboin, H. \& Vainio, H. (1992) Sex, age- and pregnancy-induced changes in the metabolism of toluene and trichloroethylene in rat liver in relation to the regulation of cytochrome P450IIE1 and P450IIC11 content. J. Pharmacol. Exp. Therap. 261, 869-874. 